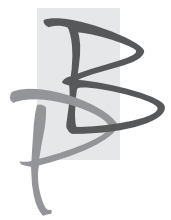

Deniz Kilinc, MSc*

Queen's University, Faculty of Law, Canada

https://orcid.org/0000-0002-5763-9222

\title{
Crossing borders: \\ Turkish Asylum Policies and Displaced Syrians' Journeys in and away from Turkey
}

Abstract: In recent years, economic, political and ecological crises throughout the world have created a monumental human flux, forming new migratory routes, spaces and challenges. As a result of these movements, distinct geographical, political, and social borders are formed and crossed, giving life to unique journeys with distinct stories. The current paper presents observations from field research and a creative expression intervention (conducted in 2015-2016) with Syrian displaced people in Turkey to illustrate the mutual relationship between Turkish asylum policies and the movements of Syrian migrants in and away from Turkey. It unpacks three different routes to contextualize the ways in which the availability and the characteristics of labour shape the mobility of displaced Syrians in Turkey. In examining the movements of people and communities through the lens of political and economic dynamics, the paper argues that displaced Syrians' mobility is largely shaped by Turkish refugee policies, which deny mi-

Deniz Kilinc is currently studying Law at Queen's University. He holds a Master of Science degree in Social and Transcultural Psychiatry at McGill University. His thesis dissertation explored processes of resilience and creative expression on the mental well-being of Syrian refugee children living outside of refugee camps in Turkey. 
grants access to legal work and condemn them to vulnerability and destitution.

Key words: Forced migration, immigration law, migrant labour, border politics, creative expression.

\section{Introduction}

"If he [the migrant] is aware of a current, a tide which is stronger than his own volition, he thinks of it, in an undifferentiated way, as Life. This view of the wholeness and inexplicability of what happens to him upholds a sense of destiny and propels a special endurance and courage. This is not to say he will never resist, that he will accept every injustice. It is to say tragedy is more real to him than explanations"1.

War, famine, oppression and injustice have always been intrinsic forces behind human migration. Journeys of crossing mountains, deserts, oceans and cities have led to endless challenges and opportunities, creating complex human currents with their own routes, spaces, systems of values, and aspirations.

Today, the ever-present hostility and the excruciating repercussions of violence and destitution around the world have resulted in the greatest migration crisis since the end of the Second World War ${ }^{2}$. Every day thousands are forced to leave their homes with memories of violence, civil unrest and poverty, traveling prolonged distances under severe pressures. Through these monumental human movements, new geographical, political and social borders are formed, crafting unique journeys with distinct stories.

In this paper I present observations collected in the course of field research with Syrian displaced people in Turkey to illustrate the relationship between

1 J. Berger, A Seventh Man, London: Writers and Readers, 1982, p. 36.

2 Trends Global, Forced displacement in 2017, "The UN Refugee Agency" 2015. 
Turkish asylum policies and the flight of Syrians in and away from Turkey. Through qualitative field notes, I argue that while every migrant has a unique story, there are interrelating external factors that ultimately define and restrict the routes they take and the spaces they come to inhabit. More specifically, I aim to illustrate the close dependency of Syrian mobility on the availability and the specific characteristics of the Turkish informal labour sector, and respectively, contribute to the field which critically examines the hegemony of discriminatory migration policies and the resulting disparity for migrant populations.

In the following pages I first present the socio-political circumstances in relation to the Syrian migrant crisis within the Turkish context and describe Turkey's asylum policies at the time of the field observations. Thereafter, I lay out the three main corridors Syrian migrants trace across Turkey and the Aegean Sea. By unpacking their journeys through these paths, I argue that Syrian migrants' movements are largely shaped by the Turkish State's asylum policies, which deny a majority of the Syrian migrants legal work and thereby confine them to the informal labour market, where they endure vulnerability and destitution.

\section{Socio-Political Context}

The Republic of Turkey was one of the only countries to maintain a relatively open-door policy for displaced Syrians in the early stages of the Syrian conflict $^{3}$. Consequently, today, Turkey holds the world's largest community of Syrian migrants: As of September 2019, over 3.6 million Syrians have been registered; about $30 \%$ of this population are hosted in official refugee camps managed by the Turkish Disaster and Emergency Management Presidency (AFAD), while the remaining majority live within the host population ${ }^{4}$.

Turkish asylum policies concerning Syrian displaced people have been evolving over the years. At the beginning of the conflict, those fleeing from Syria were classified as 'guests' rather than refugees. Two main reasons rationalized this decision. First, although Turkey is a signatory of the 1951 Conven-

3 A. Icduygu, A panorama of the international migration regime in Turkey, "Revue européenne des migrations internationals", 22 (2006): pp. 11-21.

4 United Nations Human Rights Council, Syria Regional Refugee Response http://data2.unhcr.org/en/situations/syria [Accessed: 9 May 2020].. 
tion on the Status of Refugees, its asylum policy is determined by "geographical limitation". Accordingly, the Turkish state grants refugee status only to those who flee their homes as a result of conflicts occurring in Europe and deny individuals from non-European countries of the prospect of long-term legal integration in Turkey. Second, the Turkish state assumed the conflict in Syria would come to a rapid conclusion, allowing the displaced Syrians to return home within a short period. However, as the Syrian conflict proved to be a long away from declining, and greater numbers continued to cross to the Turkish side with no clear prospect of return, in April 2013 Turkey adopted the comprehensive, EU-inspired Law on Foreigners and International Protection (LFIPT). As a result, a more dedicated legal framework for asylum in Turkey was established, which affirmed Turkey's obligation towards all persons in need of international protection, regardless of country of origin, at the level of binding domestic law. In alliance with the new law, the Temporary Protection Regulation for Syrian migrants was formalized in late October 2014. These developments granted Syrians displaced "temporary protection" status, allowing beneficiaries the right to legal stay, protection from refoulement - safeguarding Syrians against forcible return to Syria where they may be liable to be subjected to persecution and violence - and access to a set of basic rights and services, including free healthcare. At the moment, the temporary protection concept represents a prima facie, group-based approach where all nationals of Syria and stateless Palestinians originating from Syria are eligible without formal status determination, as long as they register with the Turkish Government ${ }^{5}$. However, although the new changes improved on previous policies, the Temporary Protection Regulation in its current form falls short of a stable, long-term solution. The new law does not impose a set duration on the temporary protection regime - continuation or termination of the policy going forward is entirely at the discretion of the Turkish Government , and the "geographical limitation" policy continues to bar Syrians from accessing long-term legal integration.

As part of the new law, Syrians are also granted the right to legal work, under the condition that employers must apply on behalf of employees once

5 Asylum Information Database, Introduction to the Asylum Context in Turkey https://www. asylumineurope.org/reports/country/turkey/introduction-asylum-context-turkey [Accessed: 14 November 2016]. 
residency, registration and health requirements are met (such a contract also requires the employers to pay the legal minimum wage and social security payments) ${ }^{6}$. Although this was expected to prevent the exploitation of displaced people as a source of cheap labour, decrease the dangers of radicalization, and create better overall living standards, as of late April 2016 fewer than 0.1 percent of Syrians were provided the right to legal work ${ }^{7}$. While greater numbers of applications are expected to be received by the Turkish authorities, barriers such as lack of documentation for the majority of the Syrians, unwillingness of employers to comply with the new law, bureaucracy surrounding the documentation process, and lack of proper information or access to the registration points stand out as the main reasons why the new regulation does not offer blanket access to the labour market for Syrian migrants in Turkey ${ }^{8}$.

\section{Methods}

The observations presented in the following pages were collected in two different time periods. The information about migrants' journeys in Istanbul were gathered in the summer of 2014, during my fieldwork with a group of Syrian children. For my Master's thesis I had the opportunity to establish and run a small creative expression intervention in a Syrian community centre with 18 displaced children. In addition to the intervention's main goal, providing a safe and stable environment for children to engage in artistic expression activities such as drawing, storytelling and play, I also collected in-depth field notes for research purposes. Due to the instability in the region and security reasons, I ensured the confidentiality of each participant by using alias and avoided collecting potentially incriminating data. The notes I collected explored the specific processes that took place during the activities in the intervention period and provided comments and observations on the circumstances and pressures Syrian families faced in the neighbourhood.

6 O. Karasapan, The Impact of Syrian Businesses in Turkey, "Brookings", March 16, 2016.

7 P. Kingsley, Turkey is No 'Safe Haven'for Refugees - It Shoots Them at the Border, "The Guardian", April 1, 2016.

8 T. Karas, Not Syrian, Not Turkish: Refugees Fleeing War Lack Documentation, "Aljazeera”, September 24, 2015. 
The records concerning journeys in Izmir were recorded a year after, in the summer of 2015. In the midst of writing my thesis, I decided to go back to Turkey to help a local NGO that was assisting Syrian migrants in Izmir. There, I gathered field notes while working with other volunteers to collect and disseminate food, medicine and goods to impoverished Syrians working in farms on the outskirts of the city, as well as Syrians located in the city who, in the majority, were preparing to take the journey across the Aegean Sea.

In order to analyze the field notes, I used content analysis to conceptualize all the collected data. This allowed me to find common themes and features, which were then embedded in the specific context to identify communalities in relation to the effects of Turkish asylum policies on the Syrian migrants' journeys, as well as the individual differences that emerged in response to contrasting spaces and circumstances.

\section{Three Paths into the Unknown}

In the following sections I will present three routes. Three corridors across Turkey into the remote: Istanbul, Izmir, and the Aegean Sea. While the routes follow their own direction with unique circumstances and outcomes, they share the same underlying distresses of vulnerability and destitution. Across these challenges, the corridors run into similar spaces, converging through geographical, political and cultural borders.

\section{Journey to Istanbul}

Istanbul, the economic, cultural and historic centre of Turkey, is home to over 14 million people from diverse ethnic and cultural backgrounds. It is responsible for about 20 percent of the country's industrial labour force, where the informal sector - a diversified set of economic activities, enterprises, jobs and workers that are not regulated or protected by the state - may account for up to 30 percent of the overall metropolitan economy ${ }^{9}$. In 2016 the city hosted approximately 366,000 Syrian migrants, more than the rest of Europe put together. While a small portion have substantial financial security and social networks, the majority of Syrians are left on their own to find financial means

9 OECD, Territorial Reviews: Istanbul, Turkey https://www.oecd.org/gov/oecdterritorialreviewsistanbulturkey.htm [Accessed: 2 October 2016]. 
to survive. Although formal and informal support networks provide goods and services, the increased number of arrivals over the years has resulted in a vast disparity between the needs and resources available ${ }^{10}$. Consequently, today, large numbers of Syrians either work in the informal workforce or beg on the streets.

Textile sweatshops are some of the most common places for Syrian migrants to find work in Istanbul ${ }^{11}$. Many Syrian families, including young children, work extended hours every day of the week, to earn between half and a third of the rate for the same work done by local workers ${ }^{12}$. The families in my intervention were no exception. At the beginning of their journeys, most of the families stayed with distant relatives living along the eastern border. Due to the diminished hopes of returning to Syria and the lack of work opportunities in the Eastern regions, they made their way to Istanbul. In Istanbul, they settled in neighbourhoods close to the textile industry. While my participants were not old enough to work (between the ages of 6-12), the rest of their family members engaged in degrading work at various textile sweatshops. The majority of the parents depended on their older children to contribute financially to pay for shelter and food. When asked how they feel about this, a grave sense of powerlessness and anguish were most commonly expressed. It was not a choice, but rather a form of despair.

In their struggle for survival, sweatshops become the most common spaces for many migrants' journeys in Istanbul. In a way, one can argue that they imitate the environment of a detention centre, creating a culture of economic dependence, where the migrant is left with no choice but to stay and work in the face of inequality and injustice. Moreover, as a result of the dependency, the sweatshops come to be the end of the path. Migrants enter into a cycle of exploitation, where, in most cases, the urge to survive overwhelms the urge to continue the journey forward.

10 United Nations Human Rights Council, 3RP Regional Refugee \& Resilience Plan 20152016: In Response to the Syria Crisis, Accessed October 1, 2016.

11 D. Afanasieva, In Turkish Sweatshops, Syrian Children Sew to Survive, "Reuters", July 26, 2016.

12 B. Norton, Syrian Child Refugees Making Clothes for British Companies in Turkish Sweatshops, BBC Investigation Found, "Salon", October 24, 2016. 


\section{Journey to Izmir}

Izmir, an old port city bordering Greece by the Aegean Sea, is home to one of the main Aegean sea routes taken by migrants coming from the conflicts and depressed economies of Africa, the Middle East and the Southeast Asia. Izmir is also an attractive city for a significant number of migrants who decides to stay in Turkey. Live-in farm camps on the outskirts of the city offer both shelter and work for thousands of Syria's poorest displaced. Far from the reach of health care, education and, oftentimes, electricity and clean water, most of the families live in makeshift tents around farm fields. Similar to those in Istanbul, they work extended hours for low wages. In the absence of any legal rights, the informal work conditions establish an asymmetrical power relationship, in which the migrant workers fall under the sole authority of the landowners. However, unlike Istanbul, where large ghettos offer permanent spaces for migrants to live, the seasonal nature of work in Izmir forces migrants to be constantly on the move, ready to disassemble their tents to move on to the next farm. Consequently, unstable living circumstances create a perpetual mobility in which the migrant assumes the role of a wanderer. The pressures of survival shape the route, establishing a reciprocal relationship between labour and mobility.

Yet, within the above common framework, unique stories also transpire. At the time of my volunteer work, some of the main challenges faced by migrants, besides poverty and physical violence, were racism, xenophobia, segregation and language barriers. Although the live-in farm camps were away from local neighbourhoods, the idea of migrants was commonly conjured to fuel the fear of the unknown and the reason behind the declining economy. These stereotypical perceptions and discourses were used to further establish the ground necessary to rationalize the unfair work conditions and normalise the malicious hierarchy between migrant workers and the landowners. However, in some cases these challenges were lessened through solidarity with the locals. For example, during one of our activities with migrant farm workers, several local farmers joined the migrants to sing a song that is common across both cultures; and thereafter, shared their lunch. While the interaction was brief and under the gaze of "outsiders" (NGOs), it nevertheless established a mutual space, where, for the first time, both groups came together and shared their culture and food, signalling the prospect of companionship through mutual recognition as an initial constructive step. 


\section{Journey across the Aegean}

As the crisis in Syria escalated over the years and the conditions in Turkey worsened for the migrants, the journey across the Aegean has grown more sophisticated. Increasing numbers, who cannot bear the instability surrounding their future and refuse to partake in the informal workforce under grim conditions, have been desperate to cross over to Europe, to continue their journeys in the hope of finding better living standards.

Izmir, the closest city to reach the popular islands of Chios, Samos and Lesbos, has become the main stopover for migrants from diverse backgrounds. Acting as a "melting pot of cultures, nationalities, and identities" 13 , the old city is crowded with migrants and smugglers, waiting for their turn to make the journey towards Greece. According to the UN's refugee agency, an estimated 19,140 migrants have died while trying to cross the Mediterranean since 2014, while tens of thousands of others have successfully reached southern Europe. Although the recent agreements between the European Union and the Turkish State that allow Greece to return all the "irregular migrants" back to Turkey has considerably slowed down the movement, the corridor still stands as one of the main routes for countless migrants ${ }^{14}$.

The following observations were taken during my time in Izmir in the summer of 2015, where I had the opportunity to personally meet migrant families who lived in the poor regions of Izmir. By focusing on one particular family's journey, I will present some of the common routes, spaces, agents, as well as the challenges faced by migrants who take on the life-threatening journey across the Aegean waters.

The family's journey started in Kobane, a city mainly populated with Syrians of Kurdish ethnicity. As the violence became unbearable, the family decided to cross over to Turkey to stay with distant relatives, hoping the crisis would come to an end soon so that they could return to their homes. However, as the time passed, the prospect of peace diminished and the family decided to move to Izmir, where they had higher chances of finding work.

13 J. Wood, Refugee Deal Turns Hope to Despair in Turkey's Izmir, "The National”, March 29, 2016.

14 E. Collett, The Paradox of the EU-Turkey Refugee Deal, "Migration Policy Institute", March 2016. 
At the time of our meeting, all of the family members except the youngest daughter were working at a textile sweatshop in Basmane, a neighbourhood near one of the city's main train stations. While they spent the majority of their time working to stay alive, the father of the family decided they had no future in Turkey and sold all of their personal belongings to gather money for smugglers (the price for smuggling across the Aegean changes from one smuggler to another; however, in general, it is US $\$ 1,000.00$ to $\$ 2,000.00$ ). With the decision to leave Izmir and continue their flight, the family's story entered the realm of the complete unknown. The father's daily route took on a different direction. In order to find a smuggler, he started to visit a café near their home, a well-known place filled with smugglers and fellow migrants. After consulting the owner and visiting the place over several days, he finally found a smuggler who was willing to guide the family across the Aegean. Next, the father had to buy life jackets for everybody in the family. However, since he gave almost all of their money to the smuggler, he had to shop at a black-market factory, which sold counterfeit life jackets at a much cheaper price. At the time, he was fully aware that the jackets he had bought to keep his family from drowning were filled with cheap packaging rather than proper material to keep users alive in the water. He explained that it was at this moment the "psychological" journey had started. Unlike their flight across Turkey - walking through different cities, sleeping on the streets, and working to survive - this time the journey was to the unknown, and the only thing to keep them alive, life jackets, were, in fact, useless. A sea that was a graveyard for many like him and his family stood not just as a geographical border but also as a psychological one, between them and their hopes of a better future. I have not heard anything about the family since our last meeting; I still do not have the courage to read the list of names of those who drowned that summer.

What differentiates those making the voyage across the Aegean from those choosing to stay in Izmir is a matter of complex elements. Every individual and family have their own ambitions, strengths, as well as weaknesses. That being acknowledged, it is undeniable that the overall instability surrounding Syrian migrants' legal status and the pernicious working conditions in the informal sector play a critical role in their decision to make the journey across the Aegean. In this sense, this time, instead of pulling migrants into a cycle of exploita- 
tion, the lack of conscientious labour opportunities force those migrants who do not abide them to continue their journeys, fully aware of the high chances of mortality.

\section{Reflections}

The three journeys presented in this paper illustrate unique stories with their own circumstances and challenges, where different geographical routes lead to distinct economic and social opportunities as well as barriers. In a micro sense, it would be absurd to assume that the life of a migrant working at a sweatshop in Istanbul would be the same as that of a migrant working in the farms of Izmir. Nevertheless, it is critical to recognize that beyond the differences of specific life stories, there are common macro factors which frame the direction of the routes taken by the migrants, and in doing so, mould their journeys. For displaced Syrians, Turkish asylum policies are a major factor behind their increased vulnerability and destitution. The number of difficulties to obtain work permits and the shortage of humanitarian support largely undermine their livelihood, in most cases forcing them to join the informal workforce as illegal workers. As a result, their journeys evolve according to the labour markets, where they become dependent on a system that is characterized by asymmetrical power relations. Their illegal status inevitably creates a social hierarchy in which the migrant becomes an inferior, allowing the inequality and injustice faced on a daily basis to be normalized. As a result, they are forced into ghettos, where informal work is the only option to survive. For some, though, their journey does not end there. In the face of extreme destitution and instability, some take on the ultimate journey across the Aegean, risking their lives in the hopes of safety and stability. In that instance on the boat, I imagine individual resilience and collective solidarity guide their journeys across the unknown.

\section{Conclusion}

The mutual relationship between Turkish asylum policies and the mobility of displaced Syrians, shaped by the informal workforce, highlights the intimate relationship between policy thinking, state action and public welfare. The complex nature of legal status and rights assigned to displaced Syrians in Turkey functions as an indirect regulatory vehicle with direct human consequences. 
From a macro perspective, the difficulties of obtaining legal work channels the migrant flow either into the informal sector, forming a homogeneous group of individuals who must endure similar vulnerability and destitution, or into the voyage across the Aegean, where the only two options left are either survival or death. It is within these channels that new cultural, political, economic and psychological spaces are formed. Within the context of violence, persecution and destitution, individual stories of resilience, solidarity, hope, as well as despair and pain emerge. These are the moments where we are reminded of the human nature of migration and thus the humanitarian obligation to accentuate the forgotten, or in some cases ignored, migrant stories, journeys and spaces.

\section{References}

Afanasieva, D. (2016, July 26). In Turkish Sweatshops, Syrian Children Sew to Survive. Reuters.

Anatolia News Agency (2016, September 8). Accountants Complain of Illegal Foreign Workers. Anatolia News Agency.

Asylum Information Database (2016 November 14). Introduction to the Asylum Context in Turkey.

Berger, J. (1982). A Seventh Man. London: Writers and Readers.

Collett, E. (2016, March). The Paradox of the EU-Turkey Refugee Deal. Migration Policy Institute.

Icduygu, A. (2006). A panorama of the international migration regime in Turkey. Revue européenne des migrations internationals, 22, 11-21.

Johannisson, F. (2016, January 29). Hidden Child Labour: How Syrian Refugees in Turkey are Supplying Europe with Fast Fashion. The Guardian.

Karas, T. (2015, September 24). Not Syrian, Not Turkish: Refugees Fleeing War Lack Documentation. Aljazeera.

Karasapan, O. (2016, March 16). The Impact of Syrian Businesses in Turkey. Brookings.

Kingsley, P. (2016, April 1). Turkey is No 'Safe Haven' for Refugees - It Shoots Them at the Border. The Guardian. 
Norton, B. (2016, October 24). Syrian Child Refugees Making Clothes for British Companies in Turkish Sweatshops, BBC Investigation Found. Salon.

OECD (2016, October 2). Territorial Reviews: Istanbul, Turkey.

Özden, Ş. (2013). Syrian Refugees in Turkey. MPC Research Reports 2013/05. Robert Schuman Centre for Advanced Studies, San Domenico di Fiesole (FI): European University Institute.

Squires, N. (2016, May 31). More Than 2,500 Refugees and Migrants have Died Trying to Cross the Mediterranean to Europe So Far This Year, UN Reveals. The Telegraph.

Trends Global (2015). Forced displacement in 2017. The UN Refugee Agency. United Nations Human Rights Council (2020, May 9). Syria Regional Refugee Response - Turkey.

Wood, J. (2016, March 29). Refugee Deal Turns Hope to Despair in Turkey's Izmir. The National. 